\title{
Trilhas para o enfrentamento da violência contra a mulher
}

\author{
Paula Suséli Silva de Bearzi ${ }^{1}$ (i) 0000-0003-4766-8844 \\ Aline Blaya Martins ${ }^{2}$ (iD) 0000-0001-6300-068X \\ Renato José De Marchi' ${ }^{2}$ (i) 0000-0002-7600-1240 \\ Aline Rodrigues Reser ${ }^{2}$ (i) 0000-0003-1263-4564
}

'Universidade do Vale do Taquari. Lajeado, RS, Brasil.95914-014 - ccbs@univates.br

${ }^{2}$ Universidade Federal do Rio Grande do Sul. Porto Alegre, RS, Brasil.

90040-060-ppgsc@ufrgs.br

\section{$-$}

Resumo: Neste artigo objetivamos conhecer a percepção dos profissionais da saúde da Atenção Básica a respeito de situações de violência contra a mulher e identificar quais são as estratégias utilizadas diante deste problema. Para tanto, utilizamos uma pesquisa qualitativa segundo a realização de quatro grupos focais, com posterior análise das informações por meio da técnica da Teoria Fundamentada nos Dados. Identificamos que os profissionais reconhecem a presença desta violência, porém, nem sempre há acolhimento ou intervenção. Por outro lado, alguns profissionais exemplificaram estratégias para intervir e referiram efeitos desta interferência na redução dos episódios de violência. Os resultados apresentam algumas questões que direcionam estes posicionamentos e condutas e são importantes para a reflexão sobre as potencialidades da Atenção Básica frente a este tema.

Palavras-chave: violência contra a mulher; atenção primária à saúde; profissional de saúde; teoria fundamentada.

Tracks for process of dealing with violence against women

Abstract: This research aimed to understand the perception of the health professional(s) of the primary care about violence situations against women and to identify the strategies facing this problem. Therefore, a qualitative research was carried out through four focal groups, with further analysis of the information through the technique of Grounded Theory. The professionals recognize the presence of this violence; however, there is not always a reception or intervention. On the other hand, some professionals exemplified strategies to intervene and reported the effects of this interference in the reduction of the violence episodes. The results show up some questions that guide these positions and behaviours and are important for the reflection on the potentialities of Primary Care in this area.

Keywords: Violence against women; Primary health care; Health professional; Grounded theory.

\section{Introdução}

A Organização Mundial de Saúde (OMS) reconhece a violência contra a mulher como um problema de saúde pública e direitos humanos (OMS, 2015) e adota a definição da Declaração das Nações Unidas sobre a Eliminação da Violência contra a Mulher como:

Qualquer ato de violência de gênero que causa, ou pode causar, dano físico, sexual ou mental ou sofrimento à mulher, incluindo a ameaça de tais atos, coerção ou privação arbitrária da liberdade, quer ocorra na vida pública ou privada (NAÇÕES UNIDAS, 1993, art. 1\%).

A violência contra as mulheres ainda é um problema com altas prevalências e continua sendo um tema importante de debate, principalmente por evidenciar as desigualdades e 
iniquidades existentes na sociedade patriarcal. Tanto as dimensões que se referem ao patriarcado enquanto organização social que sistematicamente favorece o homem em detrimento da mulher por meio do poder/dominação, quanto as que se referem ao gênero enquanto construção social do feminino e do masculino estão presentes nas subjetividades e nas relações estabelecidas entre homens e mulheres a partir das desigualdades de poder (Heleieth SAFFIOTI, 2015).

Dessa forma, a violência alia-se às desigualdades de gênero sustentadas por padrões patriarcais e machistas, produzindo a violência de gênero contra a mulher, a qual se difere das demais porque o motivo para que ela ocorra consiste no fato de a vítima ser mulher. Essa violência tem como base uma cultura machista e ocorre em todos os grupos sociais, não havendo limites relacionados à classe e ao desenvolvimento econômico ou cultural, embora haja grupos de mulheres que apresentam maior vulnerabilidade, podendo ocorrer por várias formas, desde ofensas até agressões físicas e sexuais (SAFFIOTI, 2015; Stela Nazareth MENEGHEL et al., 2017; Leila Posenato GARCIA; Gabriela Drummond Marques da SILVA, 2018).

O uso mais intenso dos serviços de saúde nessas situações, no entanto, tem sido reportado. Algumas pesquisas referem a uma naturalização dessa forma de violência pelos(as) profissionais de saúde, além de uma prática de atendimento voltada para os sintomas clínicos e direcionada para a medicalização, o que não resulta em cuidado adequado a essas mulheres (Rebeca Nunes Guedes de OLIVEIRA; Rosa Maria Godoy Serpa da FONSECA, 2015; Lilia Blima SCHRAIBER ef al., 2007; Ethel Bastos da SILVA; Stella Maris de Mello PADOIN; Lucila Amaral Carneiro VIANNA, 2015; Neuzileny Nery Ferreira SILVA et al., 2017).

Essa prática, relacionada a uma intervenção baseada no modelo tradicional biomédico, não se refere exclusivamente às questões de violência de gênero, mas também a outros agravos, de maneira que a complexidade da clínica tem sido discutida em busca de uma abordagem que não esteja focada apenas na doença, mas sim centrada no sujeito e seu contexto (Octávio Augusto CONTATORE; Ana Paula Serrata MALFITANO; Nelson Filice de BARROS, 2017).

Os serviços de Atenção Básica são aqueles em que os profissionais têm maior proximidade com a população, acesso frequente, constante e legitimado às mulheres, constituindo-se em um espaço potencial de prevenção e intervenção nas situações de violência (OLIVEIRA; FONSECA, 2015). Nesse sentido, observa-se a necessidade de uma melhor compreensão sobre a violência de gênero contra a mulher no campo da saúde a fim de que esse tema seja objeto de intervenção na saúde, a partir de um trabalho interdisciplinar e intersetorial, uma vez que disciplinas isoladas são insuficientes para conhecer e intervir nessa problemática (Ana Flávia Pires Lucas D'OLIVEIRA; SCHRAIBER, 2013).

As questões que nos colocamos diante do exposto foram: 1) Os(as) profissionais da saúde reconhecem e identificam a violência de gênero que ocorre no seu cotidiano de trabalho no território onde atuam? 2) Estes(as) profissionais percebem a situação da violência de gênero como um problema a ser enfrentado pela equipe de saúde? Dessa maneira, este estudo teve o objetivo de conhecer as percepções dos(as) profissionais da saúde da Atenção Básica a respeito de situações de violência de gênero e identificar quais são as estratégias utilizadas quando se deparam com casos de mulheres em situação de violência nos territórios das equipes onde atuam.

\section{Caminho metodológico}

Este estudo, de abordagem qualitativa, utilizou a técnica de entrevista de Grupos Focais (GF), com o objetivo de reunir informações sobre o tema a partir de um grupo de profissionais da Atenção Básica de um município de médio porte do sul do Brasil. Esta técnica permite o alcance de diferentes perspectivas de uma mesma questão, possibilitando captar conceitos e preconceitos, opiniões e ideias, valores, sentimentos e ações voltados para o objetivo do estudo, além de favorecer a compreensão de práticas cotidianas, atitudes e comportamentos (Leny A. Bomfim TRAD, 2009).

Nesse município foi criado em 2006 um centro de referência para atendimento às mulheres vítimas de violência e, segundo dados dos serviços, até dezembro de 2016 haviam sido atendidas 3.548 mulheres, das quais menos de 10\% haviam sido encaminhadas por profissionais de saúde, justificando a necessidade de uma maior articulação entre estes serviços.

Foram realizados dois GFs com equipes de Saúde da Família e dois com equipes do modelo de Unidade Básica de Saúde tradicional, o que permitiu variabilidade entre as categorias profissionais e experiências de trabalho. Os grupos foram realizados entre agosto e setembro de 2017 , em horário de reunião de equipe, e tiveram duração entre 60 e 90 minutos, onde os(as) participantes puderam expor seu entendimento sobre a temática a partir de perguntas disparadoras.

As discussões foram gravadas, transcritas na íntegra e inseridas no software $N V I V O \& 11$, para auxiliar no processo de codificação e organização das informações. Além da moderadora, esteve presente uma relatora. Na transcrição, cada participante recebeu um código iniciado pelas letras GF seguido pelo número do grupo focal ( 1 a 4 ) e pelo número referente àquele participante. 
A técnica escolhida para análise das informações foi a Teoria Fundamentada nos Dados (TFD), que busca estudar os fenômenos sociais e compreender de que maneira os sujeitos vivem suas experiências por meio da análise sistemática de informações, organização em categorias e elaboração de uma teoria final a partir das relações percebidas entre essas categorias (Kathy CHARMAZ, 2009). À medida que as informações foram coletadas, procedeu-se à sistematização e à análise, visto que, na TFD, a análise se dá concomitantemente à coleta.

$\mathrm{Na}$ codificação inicial realizamos minuciosa exploração das informações, fazendo a codificação linha a linha e atribuindo palavras ou expressões que deram origem aos códigos preliminares. Na segunda etapa realizamos a codificação focalizada, na qual os códigos oriundos da codificação inicial foram reagrupados e inter-relacionados em um nível maior de abstração. A construção das categorias originou-se por meio das várias leituras das informações, comparação de códigos iniciais, construção de mapas de ideias e representações gráficas na forma de esquemas, procurando encontrar uma interação e integração entre os códigos. A coleta de informações encerrou-se quando houve saturação, ou seja, as informações produzidas em novas entrevistas tornaram-se repetitivas e sem novas informações relevantes para a análise, estudo das categorias e compreensão do fenômeno (CHARMAZ, 2009).

Este estudo foi aprovado pelo Comitê de Ética em Pesquisa da Universidade Federal do Rio Grande do Sul, parecer n ${ }^{\circ}$ CAAE 69737517.0.0000.5347, e os(as) participantes autorizaram o uso das informações mediante assinatura do Termo de Consentimento Livre e Esclarecido.

\section{Descobrindo as indicações da trilha}

O número de participantes em cada grupo variou de quatro a doze pessoas, totalizando 36 participantes. Observou-se que a maioria dos(as) profissionais trabalha na Atenção Básica e na mesma equipe há mais de 2 (dois) anos, o que favoreceu a abordagem da temática no grupo e uma participação ativa na discussão. A análise do perfil demonstrou apenas 3 (três) profissionais homens, o que apontou que as mulheres constituem a maioria dos(as) profissionais que atendem nas unidades de saúde, o que já ficou evidente em outros estudos (Alessandra Bernadete Trovó de MARQUI et al. , 2010; Regina Maria Giffoni MARSIGLIA, 201 1; Mônica WERMELINGER et al., 2010). A feminização do setor saúde tem sido observada principalmente a partir da década de 1970, com a progressiva ampliação da participação das mulheres, que passaram a atuar especialmente nas funções relacionadas aos cuidados, o que leva a uma necessária problematização sobre a naturalização do papel da mulher na sociedade enquanto cuidadora da família e a casa (WERMELINGER et al., 2010).

Outro fato importante que estimulou as discussões foi que em todos os grupos houve relatos pessoais de vivência da violência, assim como de atendimento às mulheres vítimas, tanto entre as pessoas jovens quanto entre as com mais idade. Apesar de haver um grupo de pessoas com menos de 2 anos de atuação na atenção básica, caracterizado por um vínculo de trabalho precário, a maioria dos(das) participantes possuía vínculo de trabalho estável, com atuação na atenção básica entre 2 e 10 anos, o que foi levado em consideração na análise das informações, uma vez que este fato favorece uma maior vinculação da equipe com a comunidade. Os núcleos profissionais e o perfil dos(das) participantes encontram-se no Quadro 1.

A partir da análise das informações e das codificações realizadas, emergiram três categorias analíticas. A construção da primeira categoria, Reconhecimento da violência de gênero contra a mulher, surgiu a partir dos relatos de vivências pessoais e narrativas trazidas por usuárias em atendimentos, sendo estas experiências reconhecidas como cotidianas. Frente a este reconhecimento surgiram relatos relacionados às condutas que foram ou não tomadas, o que fez emergir a categoria seguinte: Condutas frente à violência de gênero contra a mulher.

Esta segunda categoria trouxe à tona a omissão e naturalização dos episódios de um lado e, de outro, a mobilização e intervenção baseadas no vínculo e no acolhimento. Ao se questionarem sobre a decisão de intervir ou não, foram pontuadas questões relacionadas à rede de atendimento, compiladas na terceira categoria: Rede de atendimento à mulher em situação de violência. Esta categoria ajuda a entender o contexto e articula-se com as demais a partir da percepção de que a rede de atendimento precisa estar fortalecida para dar suporte às ações executadas na Atenção Básica, a fim de favorecer condutas menos fragmentadas e que tenham potencial de reduzir episódios de violência.

Os resultados e a discussão são apresentados em conjunto para que seja possível interpretar e compreender as informações de maneira integrada, à luz da literatura atual e a partir das falas dos sujeitos. 


\begin{tabular}{|c|c|c|c|c|c|c|}
\hline & Côligo & IDADE & FUNCÃO & $\begin{array}{c}\text { TEMPO DE } \\
\text { ATUACAO } \\
\text { NA AB }\end{array}$ & $\begin{array}{l}\text { VIOLENCLA } \\
\text { FAMILIAR } \\
\text { RELATADA }\end{array}$ & $\begin{array}{l}\text { ATENDEU } \\
\text { VITIMA DE } \\
\text { VIOLECIA }\end{array}$ \\
\hline \multirow{8}{*}{ 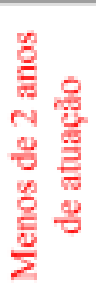 } & GF3 2 & 25 & Médica & 6 meses & & \\
\hline & GF2 11 & 28 & Higienizadora & 1,6 anos & & \\
\hline & GF3 4 & 28 & Enfermeira & 2 anos & Sim & Sim \\
\hline & GF2 10 & 32 & ASB & 2 anos & Sim & Sim \\
\hline & GF2 3 & 33 & $\mathrm{ACS}$ & 1,5 anos & & Sim \\
\hline & GF4 3 & 46 & Higienizadora & 1,5 anos & Sim & \\
\hline & $\mathrm{GF} 42$ & 51 & Administrativa & 2 anos & & Sim \\
\hline & GF1 I & 52 & ASB & 2 anos & & Sim \\
\hline \multirow{19}{*}{ 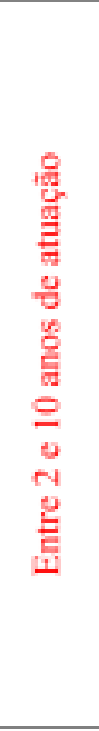 } & GF3 10 & 22 & Téc. Enf & 3 anos & & Sim \\
\hline & GF3 9 & 25 & $\mathrm{ACS}$ & 3 anos & Sim & \\
\hline & GF2 5 & 28 & Téc. Enf & 9 anos & Sim & Sim \\
\hline & GF2 9 & 30 & $\mathrm{ACS}$ & 9 anos & Sim & \\
\hline & GF4_I & 32 & Enfermeira & 6 anos & & Sim \\
\hline & GF3 I & 32 & ASB & 8 anos & Sim & Sim \\
\hline & GF2 12 & 33 & Enfermeira & 9 anos & & Sim \\
\hline & GF2 7 & 36 & $\mathrm{ACS}$ & 9 anos & Sim & Sim \\
\hline & GF3 7 & 40 & $\mathrm{ACS}$ & 10 anos & Sim & Sim \\
\hline & $\mathrm{GF} 22$ & 42 & $\mathrm{ACS}$ & 9 anos & Sim & Sim \\
\hline & GF1 3 & 51 & Higienizadora & 4 anos & Sim & \\
\hline & GFI 6 & 51 & Higienizadora & 8 anos & & \\
\hline & GF3 11 & 52 & $\mathrm{ACS}$ & 3 anos & Sim & \\
\hline & GF2 6 & 53 & $\mathrm{ACS}$ & 8 anos & Sim & Sim \\
\hline & GF4 4 & 53 & Téc. Enf. & 10 anos & & Sim \\
\hline & GFI 8 & 57 & Administrativa & 3 anos & & \\
\hline & GF3 8 & 57 & ACS & 10 anos & & \\
\hline & GF3 6 & 59 & $\mathrm{ACS}$ & 9 anos & & \\
\hline & GF2 4 & 62 & $\mathrm{ACS}$ & 9 anos & Sim & \\
\hline \multirow{9}{*}{ 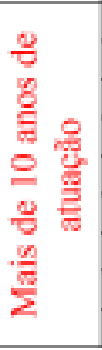 } & GF1 5 & 34 & Enfermeira & 12 anos & & Sim \\
\hline & GF1 4 & 49 & Téc. Enf & 15 anos & & \\
\hline & GF1 9 & 50 & Enfermeira & 20 anos & & Sim \\
\hline & GF3 3 & 53 & Téc. Enf. & 15 anos & & \\
\hline & GF1 2 & 55 & Téc. Enf & 20 anos & & \\
\hline & GFI 7 & 58 & Nutricionista & 12 anos & & Sim \\
\hline & GF2_1 & 59 & ACS (homem) & 19 anos & & \\
\hline & GF2 8 & 60 & $\mathrm{ACS}$ (homem) & 19 anos & & Sim \\
\hline & GF3 5 & 71 & Dentista (homem) & $23 \operatorname{anos}$ & & Sim \\
\hline
\end{tabular}

Quadro 1: Perfil dos participantes

Fonte: Elaborado pela autora.

\#PraTodoMundoVer Quadro do perfil dos participantes sobre fundo branco, contendo sete colunas e trinta e sete linhas. A primeira coluna apresenta os participantes em três grupos de acordo o tempo de atuação: menos de dois anos, entre dois e dez anos e mais de dez anos. A segunda traz o código do participante, a terceira a idade em ordem crescente, a quarta a função e a quinta o tempo de atuação. Já a sexta apresenta se houve experiência de violência familiar relatada e a sétima se houve atendimento à vítima de violência. Oiło participantes estão no grupo com menos de dois anos de atuação, com idades entre 25 e 52 anos, funções de médica, higienizadora, auxiliar de saúde bucal, agente comunitária de saúde e administrativa, com relatos de violência familiar e atendimento a vítimas. O grupo com atuação entre dois e dez anos tem dezenove participantes com idades entre 22 e 62 anos, funções de técnica de enfermagem, agente comunitária de saúde, enfermeira, auxiliar de saúde bucal, higienizadora e administrativa, com relatos de violência familiar e atendimento a vítimas. Nove participantes, com idades entre 34 e 71 anos, estão no grupo com mais e dez anos de atuação, com funções de enfermeira, técnica de enfermagem, nutricionista, agente comunitário de saúde e dentista, sendo três homens, com relatos de atendimento a vítimas.

\section{Reconhecimento da violência de gênero contra a mulher}

A violência de gênero contra a mulher foi identificada pelos(as) participantes dos grupos focais como uma situação que afeta as mulheres com grande frequência por meio de experiências diárias de discriminação e opressão. Os relatos trazidos pelos(as) participantes demonstraram a presença de situações de violência tanto no âmbito privado quanto público, e várias foram as falas que trouxeram vivências pessoais:

Eu também sofri... pessoal mesmo, vendo a minha vó apanhar do meu vô, a minha mãe apanhar do meu pai, e assim foi, e eu também. Durante dez anos, eu era... Eu apanhava, eu era mantida em cativeiro (GF2_7). 
Essa fala, além de trazer a vivência pessoal, expressa uma violência que atravessou gerações, o que foi pontuado também por outras participantes. Os relatos partiram de diferentes contextos e histórias de vida, trazendo experiências de assédio sexual em via pública e no espaço de trabalho, relação sexual forçada pelo parceiro, violência física, humilhação e violência patrimonial causando dependência financeira da família em relação ao agressor, com casos em que houve rompimento e outros que se mantêm. Além disso, as participantes relataram que a violência não afeta só as mulheres, mas que seus filhos também são agredidos e sofrem as consequências, o que já foi apontado (Eva ESPINAR-RUIZ; Begoña LOPEZ-MONSALVE, 2015; OMS, 2015). No entanto, observou-se que há uma naturalização de muitas atitudes violentas no ambiente doméstico enquanto meio de educação dos filhos, assim como um entendimento de que a agressão muitas vezes é 'sem maldade', ou seja, ela estaria tão intrínseca na relação que o homem não vê sua atitude como um ato de violência, sendo um comportamento naturalizado e entendido como comum à sua natureza, além do mais, é 'genética':

$E$ eu acho que ele faz aquilo ali, mas sem maldade [...] É uma coisa que a pessoa não... O homem não se dá por conta [...] Sabe, porque aquilo é uma coisa genética, aquela explosividade é uma coisa genética (GF2_8).

Apesar de essa fala vir de um homem, muitas mulheres presentes no grupo concordaram. Destaca-se essa aparente contradição em que, de um lado, os(as) participantes identificam a violência e sua gravidade e, de outro, ainda consideram naturais algumas práticas violentas. É importante observar que a sociedade tolera e até incentiva que homens demonstrem sua força e dominação contra as mulheres, assim como que pais e mães batam em seus filhos (SAFFIOTI, 2015). As palmadas costumam acompanhar o desenvolvimento de muitas crianças, o que faz com que se estabeleça desde cedo uma associação entre amor e violência e contribui para a naturalização das ações violentas (Luciana Santos RODRIGUES; Anderson Almeida CHALHUB, 2014).

Autores(as) têm referido que a atitude violenta está direcionada ao ataque da subjetividade do outro, e aparece quando as relações de poder estão ameaçadas, sendo um ato influenciado por fatores históricos, sociais, culturais e subjetivos (SAFFIOTI, 2015; RODRIGUES; CHALHUB, 2014; MENEGHEL; Ane Freitas MARGARITES, 2017). Nesse sentido, a violência de gênero contra as mulheres precisa ser tratada como um problema estrutural de uma sociedade patriarcal e não como um problema individual (Bruna KRIMBERG VON MÜHLEN; Marlene NEVES, 2013).

Quanto às usuárias, os(as) profissionais relataram que é comum que elas não tragam essa questão como queixa principal e não exponham essa condição, apesar de muitas vezes eles(as) identificarem nos atendimentos de saúde situações frequentes e que se repetem, havendo um ocultamento por parte da vítima, como já referido (OMS, 2015; SCHRAIBER et al., 2007). A dificuldade de visualização e o ocultamento dessa situação passam por alguns fatores, como a violência ocorrer em âmbito privado e estar relacionada a sentimentos de medo e vergonha, que impedem a mulher de torná-la pública (KRIMBERG VON MÜHLEN; NEVES, 2013; Gustavo VENTURINI; Tatau GODINHO, 2013; OMS, 2015). Foram evidenciadas ocorrências de usuárias que relataram situações de violência durante consultas por outros motivos ou ainda descreveram situações que estavam vivenciando durante visitas domiciliares dos(as) Agentes Comunitários(as) de Saúde (ACS):

Acontece muito. O agente comunitário de saúde é bem fácil de identificar, porque a gente vai no dia a dia (GF2_2).

$\hat{E}$, eu vejo bastante, principalmente nas consultas de coleta de CP (pré-câncer) e testes rápidos (GF3_4).

As diversas formas como essas violências se expressam estiveram presentes nos relatos por meio de exemplos de violência psicológica, moral, física, sexual e patrimonial relatadas pelas usuárias. Apesar de ser possível identificar o reconhecimento da violência de gênero contra a mulher para além do âmbito doméstico, os relatos mais frequentes estiveram relacionados à violência conjugal ou familiar, o que está em consonância com a literatura, que mostra que as mulheres são agredidas, na maioria das vezes, por homens que elas conhecem e que mantêm relações (MENEGHEL; MARGARITES, 2017; OMS, 2015; KRIMBERG VON MÜHLEN; NEVES, 2013; VENTURINI; GODINHO, 2013). Desse modo, além da dor causada pela agressão em si, existe a dor pelo fato de a agressão vir de alguém com quem a vítima possui vínculos afetivos.

Ao contrário do que identificamos, o que tem sido observado com maior frequência nas pesquisas da área é o não reconhecimento das situações de violência vivenciadas pelas usuárias e de suas consequências para a saúde pelos(as) profissionais de saúde (SCHRAIBER et al., 2007; KRIMBERG VON MÜHLEN; NEVES, 2013; Elisabeth Meloni VIEIRA; Mariana HASSE, 2017). Salientamos que, apesar desse reconhecimento estar presente em todos os grupos realizados, nem sempre houve uma intervenção por parte dos(as) profissionais.

Foi referido que, muitas vezes, há uma dificuldade de a mulher perceber-se vítima de violência, o que influencia para que a relação conjugal seja mantida. Alguns relatos relacionaram 
essa condição a uma doença crônica, a qual é antiga, está presente há muito tempo e para a qual é difícil achar uma solução:

Então é uma situação antiga, [...] mas parece que quanto mais antigo mais difícil de buscar solução, né? Por que é, eu acho que é, como uma doença, né? Crônica. (GF4_4).

Em seu estudo com doentes crônicos, Kathy Charmaz (1990) refere que as características de cronicidade de um agravo não são identificadas imediatamente, somente após semanas e meses de sintomas recorrentes que as pessoas passam a perceber os efeitos que a doença produz na vida cotidiana, a partir das alterações que precisam fazer na sua rotina a cada dia. Nesse sentido, pode-se traçar um paralelo com a condição em que vivem algumas mulheres em situação de violência, que ao não conseguirem romper com a violência convivem cronicamente com essa situação, tendo que lidar diariamente com seus efeitos, os quais produzem sofrimento, diminuição da autoestima, medo, isolamento social e incorporação do sentimento de culpa que acaba por distanciar a mulher das possíveis redes sociais de apoio (Gabriela Cristina Costa de OLIVEIRA; Maione Silva Louzada PAES, 2014). Esta situação também pode ser relacionada à dificuldade de alguns profissionais lidarem com estas mulheres que não rompem com essa situação: elas são vistas como aquelas usuárias em que não adianta investir, que não há nada o que fazer, que é uma escolha delas se manter nessa situação, ignorando a complexidade de fatores psicológicos e sociais envolvidos nessas relações (KRIMBERG VON MÜHLEN; NEVES, 2013).

A atuação dos(as) profissionais de saúde nas situações de violência de gênero contra a mulher tem relação com conhecimento ou desconhecimento teórico e técnico sobre a temática, assim como pelas explicações, crenças e ideias dos mesmos. Nesse sentido, aprofundamos a análise para buscar compreender quais são os fatores motivadores para intervir ou não e quais são as estratégias que são utilizadas.

\section{Condutas frente à violência de gênero contra a mulher}

\section{Deixando de agir frente à violência}

É comum que frente a situações de violência os(as) profissionais paralisem, não agindo e nem buscando explicações para os sinais e sintomas que se apresentam, o que resulta em falta de registros adequados e faz com que este problema se mantenha invisibilizado (SCHRAIBER et al., 2007; KRIMBERG VON MÜHLEN; NEVES, 2013). Vários(as) profissionais relataram dificuldades em abordar essa temática, referindo não saber como perguntar sobre a questão e que as usuárias costumam esconder a situação, não havendo o que fazer nesses casos:

Eu não tenho coragem de chegar e perguntar 'tá, mas, o que que aconteceu no teu olho, o teu marido que te bateu'? Eu não sei como fazer esse tipo de pergunta (GF3_1).

Também referiram pensar que sua ação não terá resultado, pontuando que não possuem os conhecimentos e habilidades necessários para esse tipo de abordagem:

Tipo... que isso é uma violência, assim, a violência tá muito presente. Só que é um tema muito delicado. E na formação eu acho que ninguém tá preparado pra isso (GF3_4).

Não agir também é uma conduta frente à violência de gênero contra a mulher e produz um resultado, que é o da manutenção da situação. Observou-se que deixar de acolher as situações de violência, a partir de suspeitas observadas por meio de falas indiretas, queixas inespecíficas e até marcas físicas, mantém o problema invisibilizado e faz com que as mulheres não identifiquem o serviço de saúde como um serviço de suporte que elas possam buscar para romper com a violência. Os motivos que foram relatados para essa não intervenção foram múltiplos e estão relacionados principalmente a não estar capacitado, entender que este é um problema privado e não reconhecer uma rede de atendimento. Percebemos também que a maioria dos(as) profissionais desconhece os serviços que podem ser acionados para o atendimento à mulher em situação de violência, e que, quando há conhecimento, os serviços são apontados de forma isolada e sem ter clareza quanto às formas de acesso, o que também foi identificado em outras pesquisas (OLIVEIRA; FONSECA, 2015; Ana Flávia Pires Lucas D’OLIVEIRA et al., 2009).

Porém, cabe questionar e refletir sobre qual seria a capacitação necessária para esse atendimento. Para Schraiber e D'Oliveira (2009), a invisibilidade da violência no campo da saúde está relacionada a uma recusa tecnológica, e a superação dessa dificuldade passa pela aquisição e compreensão de ferramentas que privilegiem a capacidade de diálogo. Nesse sentido, Emerson Elias Merhy e Laura Camargo Macruz Feuerwerker (2009, p. 36), falando sobre as tecnologias relacionais e os atos de saúde, referem que "produzir atos de saúde cuidadores é tarefa a ser compartilhada por todos os trabalhadores de uma unidade de saúde. Todos podem acolher, escutar, interessar-se, contribuir para a construção de relações de confiança e conforto". Há que se destacar que esta invisibilidade não está só no campo da saúde, mas também diz 
respeito a um processo cultural e histórico que oculta e, por vezes, nega este fenômeno. De fato, a invisibilidade da mulher é resultado de um modelo patriarcal no qual está baseada a estrutura social e que permeia as relações da sociedade em diversos campos, incluindo aí a saúde, a educação e o trabalho e, portanto, também se manifesta no Sistema Único de Saúde (Marlene Neves STREY; Graziela C. WERBA, 2012; SAFFIOTI, 2015).

Ressaltamos que a Atenção Básica se constitui em um importante espaço para o enfrentamento dessa forma de violência, devido à sua proximidade com as usuárias e o território, assim como pelo fato de ter seu trabalho pautado pelas tecnologias relacionais e pela atenção integral aos usuários (Tatiana das Neves Fraga MOREIRA et al., 2014; BRASIL, 2016). Entretanto, é comum que profissionais de saúde atuem de forma procedimental e reproduzam a presunção de obediência e aceitação incondicional, prescrevendo medicações e atitudes como para um sujeito que está isolado do seu meio social, desconsiderando sua autonomia (CONTATORE; MALFITANO; BARROS, 2017).

Este é um ponto crucial para esta discussão, pois não há como produzir mudanças enquanto as ações em saúde estiverem pautadas no processo de trabalho centrado neste modelo biomédico. É preciso comprometimento com o cuidado centrado na pessoa para identificar, enfrentar e acompanhar esse problema, oferecendo acolhimento com escuta qualificada, solidária e sem culpabilização (D'OLIVEIRA et al., 2009; Regina VARGAS, 2015). Nesse sentido, há que se pensar estratégias para que este tema faça parte do trabalho e das discussões da equipe a partir dos casos identificados no território e do conhecimento teórico e técnico sobre o problema.

\section{Intervindo para redução da violência}

Por outro lado, foi possível observar diversos relatos em que houve uma mobilização frente a algumas situações. O elemento que se refere à idade da vítima ficou bastante aparente, havendo uma sensibilização maior quando a vítima era muito jovem ou idosa:

Ela é uma menina nova, tem toda uma vida pela frente [...] Mas ela tá desanimada, ele minou a autoestima [...] eu vou lá quase todo dia (GF2_6).

Porque bah, mexeu, era uma idosa de setenta e poucos anos, alguma atitude eu tinha que tomar (GF2_2).

Quanto às mulheres jovens foi possível observar que há uma expectativa maior quanto à possibilidade de rompimento com a situação, ou até mesmo de intervenção a partir do Conselho Tutelar quando envolvia adolescentes. Já no que se refere às mulheres idosas, a mobilização é pelo motivo inverso: não se vislumbra a possibilidade de rompimento, e a tentativa de intervenção era para diminuir a frequência e gravidade dos episódios de violência. Outro estudo sobre atendimento a situações de violência doméstica por equipes de Saúde da Família também apontou que as equipes agiam principalmente em situações de violência contra idosos(as) e crianças/adolescentes, em detrimento de situações de violência contra a mulher (MOREIRA et al., 2014).

Os(as) ACSs relataram algumas estratégias utilizadas para abordar a situação e tentar intervir, como orientação sobre a rede de atendimento, maior frequência de visitas e aproximação com a vítima e também com o agressor:

A minha estratégia foi de visitar mais vezes esse casal, e me achegar nele, que é o agressor, fazendo uma amizade com ele (GF2_2).

Outro dia eu voltei lá [...] eu disse, 'tu sabe que tu tem os teus direitos?' (GF2_7).

Estes(as) profissionais, em geral, encontram facilidade de acesso aos domicílios e possuem uma relação com as usuárias de maior proximidade, além do conhecimento a respeito da rede de apoio comunitário que pode ser acionada, fatores que foram identificados por eles(as) como potenciais para a intervenção. ACSs têm um papel fundamental na identificação de casos e prestação de cuidados a essas mulheres por estabelecerem uma relação mais horizontal com as usuárias e estarem presentes frequentemente no espaço doméstico, no entanto, este não é um tema individual, sendo imprescindível que haja um trabalho em equipe com discussão dessa problemática nas reuniões e formações a fim de planejar e intervenções qualificadas (Marcos Claudio SIGNORELLI; Angela TAFT; Pedro Paulo Gomes PEREIRA, 2018). As condutas que foram realizadas nos atendimentos na UBS direcionaram-se para a orientação quanto às relações sexuais não consentidas, orientações quanto à rede de apoio e notificação, esta última com pouca frequência e mais relacionada a situações de violência física. O estabelecimento de vínculo apareceu como a principal estratégia para o enfrentamento dessa forma de violência:

Fiz o melhor pra ela e eu vi no rosto dela que quando eu saí ela ficou bem. Por causa do vínculo (GF2_2).

Eu tenho vínculo, tu tem vínculo, a enfermeira tem vínculo, a doutora tem vínculo. $E$ dentro de um vínculo, a gente se juntando pode planejar uma ação conjunta (GF2_8). 
O vínculo está relacionado a uma postura profissional de corresponsabilização a partir de relações afetivas e efetivas com respostas adequadas às necessidades das pessoas, constituindose em um elemento que potencializa a capacidade resolutiva dos serviços (Juliana de Lima SOARES et al., 2016). A configuração de relações de confiança e proximidade pode possibilitar que seja gerada uma intervenção potente nas situações de violência, o que também é uma aposta do Projeto Mulheres da Paz, que enfrenta esta problemática por meio do trabalho de mulheres da própria comunidade (Vinicius Assis COUTO et al., 2018). A abordagem a partir do vínculo e da escuta esteve presente a partir da abertura para abordar o problema dentro dos serviços de saúde ou em visitas domiciliares:

A primeira coisa é o serviço se colocar disponível. As mulheres enxergarem o serviço como um local de escuta, o trabalhador se colocar numa posição de escuta. Eu vejo que na maioria das vezes o posto de saúde é o único local que elas conseguem falar sobre isso (GF2_12).

A escuta acolhedora, não julgadora e ativa é o ponto principal para contribuir com que as mulheres encontrem estratégias de enfrentamento (BRASIL, 2016; OLIVEIRA; FONSECA, 2015; D'OLIVEIRA et al., 2009). Dessa forma, a ênfase deve estar no processo de superação da violência, que vai ser diferente para cada mulher, de acordo com o que é possível fazer e com o tempo necessário em cada situação (VARGAS, 2015). A busca por alternativas e a não determinação de ações esteve presente nas falas:

Eu acho que a gente, é bem isso [...] a gente tem que... Tipo assim, dar opções, entende. Saber ofertar opções pra pessoa, pra que assim ela decida, né? (GF2_5).

D'Oliveira e colaboradoras (2009) propõem que os(as) profissionais sejam treinados para uma técnica de conversa, cuja base é a escuta qualificada para detecção e orientação de mulheres em situação de violência, com vistas ao fortalecimento e crítica à banalização da violência e das desigualdades de gênero, seguindo princípios de disponibilidade de tempo, privacidade, sigilo, acolhimento, vínculo e confiança. O Protocolo de Saúde das Mulheres (BRASIL, 2016) traz uma série de orientações quanto ao acolhimento às vítimas de violência com escuta qualificada, sendo um importante documento a ser trabalhado pelas equipes, porém, não surgiram relatos referentes ao conhecimento desse documento nem do Caderno de Atenção Básica n 8 Violência Intrafamiliar (BRASIL, 2001) ou da Norma Técnica para prevenção e tratamento dos agravos resultantes da violência sexual contra mulheres e adolescentes (BRASIL, 2012). A notificação compulsória (BRASIL, 2003) foi referida por alguns profissionais, ainda que os mesmos relatem que não fazem uso frequente da mesma. Dessa forma, o reconhecimento do problema e a decisão/ possibilidade de intervir ou não intervir estiveram mais relacionadas às vivências e experiências individuais de cada um do que com um conhecimento teórico e técnico sobre a temática.

A Estratégia de Saúde da Família foi reconhecida pelos(as) participantes como o modelo de atenção à saúde com maior potencial para identificar e intervir nas situações de violência, como já apontado em outros estudos (MOREIRA et al., 2014; SIGNORELLI; TAFT; PEREIRA, 2018), e os(as) ACSs relataram perceber o espaço de escuta como terapêutico e sua proximidade com as famílias como um fator protetivo.

Desse modo, foi possível observar que os(as) profissionais conseguiram exemplificar diversas estratégias para intervir nas situações de violência que identificaram, como a disponibilidade para escuta, aumento da frequência das visitas e aproximação com a vítima e agressor. Também referiram visualizar alguns efeitos dessa interferência na redução dos episódios de violência e na identificação de uma rede de apoio.

Ela se pinta, ela sorri, eu vejo ela todos os dias na rua, coisa que não se via [...] Eu acho que intimidou ele, né, porque viu que tinha alguém por ela (GF2_7).

Percebi que quanto mais eu estou junto dessa família, junto desse casal, menos ele agrediu ela, menos ele colocou ela pra fora (GF2_2).

Outro aspecto apontado foi a possibilidade de intervenção que todos(as) os(as) profissionais da equipe têm, colocando a equipe enquanto rede de apoio e suporte e ampliando o olhar para identificar as situações. A constituição da violência enquanto objeto de intervenção na área da saúde depende da postura individual, mas também da postura da equipe frente ao problema. Isto exige uma discussão da abordagem, dos instrumentos, dos saberes que precisam ser mobilizados e apoio às condutas, com a finalidade de fortalecer as mulheres para além de aliviar a dor e tratar os sintomas decorrentes. A equipe também deve buscar seu fortalecimento, atuando na direção da elaboração de projetos terapêuticos singulares negociados e construídos em conjunto para cada caso, tendo como referência a garantia de direitos e reconhecendo a violência contra a mulher como um problema público (D'OLIVEIRA et al., 2009).

Cabe ainda ressaltar que a notificação é um importante instrumento de política pública, devendo ser discutida entre os profissionais das diversas áreas, não só do setor saúde. Porém, mais 
importante que notificar é a articulação em rede que permita traçar planos terapêuticos e mobilizar apoio intersetorial para dar significado às notificações e produzir ações de enfrentamento à violência.

\section{Rede de atendimento à mulher em situação de violência}

Alguns serviços foram identificados pelos(as) participantes dos grupos como integrantes da rede de atendimento às mulheres em situação de violência no município estudado: Centro de Referência em Assistência Social (CRAS), Centro de referência para atendimento às mulheres em situação de violência, Hospital Geral e Delegacias. Além disso, a Atenção Básica foi identificada como uma parte importante da rede de atendimento à mulher em situação de violência, porém com dificuldades de articulação com os demais serviços.

Ficou aparente um desconhecimento de outros serviços e também quanto aos fluxos para acesso daqueles que são identificados. Outro ponto bastante criticado foi a burocracia, que faz com que muitas mulheres desistam de procurar os serviços. A fragmentação entre os próprios serviços da rede de atenção à saúde, onde se evidencia a dificuldade de comunicação entre os pontos de atenção, foi assinalada como mais uma das fragilidades dessa rede:

Houve uma mesma denúncia pra um mesmo órgão, enfim, de vários pontos de saúde diferentes, ou de atendimento na UPA (unidade de pronto atendimento), atendimento no hospital, atendimento no posto de saúde do bairro, e nada, não andou, não foi pra frente, não tomou uma outra instância. Essa mulher só conseguiu ter três denúncias de três profissionais diferentes, enfim, ou três encaminhamentos diferentes, e ponto, e ficou ali, ela não... Não sentiu um suporte, ali ela era sozinha (GF2_10).

Nessa situação citada, o problema não foi a falta de acesso, mas a falta de responsabilização e articulação dos serviços. Salientamos nas falas uma identificação dos serviços de saúde enquanto componentes da rede, mas uma dificuldade dos(as) profissionais se colocarem no lugar de responsabilização pela coordenação do cuidado e de articuladores da rede. Esse não é um problema de articulação apenas dos serviços de saúde, como foi apontado em outros estudos, onde se salientou as dificuldades de articulação da rede de atendimento à mulher vítima de violência e a fragmentação das ações (Cecília MacDowell SANTOS, 2015; COUTO et al., 2018).

É importante que a entrada nessa rede possa ocorrer em qualquer ponto de atendimento, no entanto, tem que haver uma horizontalidade entre os serviços que permita a circulação entre os mesmos, tanto das usuárias, quanto das informações entre os(as) profissionais, buscando um agir conjunto e integrado, formulando projetos de intervenção que se potencializem em cada ponto de atenção em que a mulher for atendida (D'OLIVEIRA; SCHRAIBER, 2013).

Apesar da grande maioria das falas apontarem para a escassez de serviços e fragilidade de integração entre os existentes, houve relatos de identificação de espaços potenciais para aproximação entre os profissionais dos diversos serviços, como as reuniões mensais da Rede Socioassistencial, que busca reunir serviços intersetoriais de uma mesma região e ocorrem nas cinco regiões do município:

O que eu achei legal da reunião de rede que eu fui no mês passado, as meninas do Jacobina (Centro de Referência para Atendimento às Mulheres em Situação de Violência), elas vão na reunião de rede também. E elas se colocaram à disposição assim, para as equipes que quiserem saber mais sobre o assunto, como funciona [...] Elas vêm até a Unidade, se a gente quiser (GF3_9).

Estas reuniões buscam reunir escolas, serviços de saúde, organizações não governamentais, serviços da assistência social e outros que possam contribuir para a integração das ações e melhorar a comunicação entre as(os) profissionais. Um desdobramento dessas reuniões diz respeito às chamadas microrredes, que são espaços para articular serviços em torno de um caso específico, construindo projetos terapêuticos conjuntos. Importante destacar que a rede de atendimento faz parte da rede de enfrentamento à violência contra a mulher, que deve ser mais ampla quanto for possível, de maneira que as reuniões da rede socioassistencial contribuam para sua tessitura.

Santos (2015) refere que existem várias redes, governamentais e não governamentais, com diferentes instituições e objetivos, com serviços articulados em maior ou menor grau, e que o principal não é identificar e mapear todas elas, mas sim identificar qual rede acionar quando necessário.

Diferentemente do que se observa em relação às mulheres, quando são relatadas situações envolvendo crianças, há um reconhecimento, mesmo que incipiente, de uma rede para acolhimento e atendimento a essas vítimas, sendo citado o Conselho Tutelar e o Ministério Público como recursos.

Mesmo a rede do município sendo insuficiente para o enfrentamento da violência de gênero contra a mulher, é necessário que os serviços existentes estejam articulados e que a Atenção Básica se integre a ela, sendo que o primeiro passo é a identificação da violência pelos profissionais. A existência de guias com a localização e horário de funcionamento dos serviços pode facilitar o 
atendimento das mulheres, assim como o conhecimento dos recursos disponíveis pode ajudar a visibilizar a rede e também demonstrar que este é um problema coletivo e social, e não individual (D'OLIVEIRA et al., 2009).

\section{Encontrando caminhos na relação entre as categorias}

A partir da análise detalhada das categorias que emergiram e comparação constante entre elas, compreendeu-se que a decisão sobre as condutas frente ao reconhecimento da violência de gênero contra as mulheres na Atenção Básica pode ocorrer por meio da aposta na construção de rede de apoio e nas tecnologias relacionais ou através de uma decisão de não acolher/intervir. Essa decisão leva em conta a percepção dos profissionais sobre o que podem ofertar para as usuárias, qual resultado é esperado se intervirem e se há uma identificação de uma rede de atendimento intersetorial que pode ser acionada.

Se o entendimento for de que é possível ofertar espaço de escuta e acolhimento, são realizadas algumas ações nesse sentido, visando à construção de vínculo e de rede de apoio. Encaminhamentos realizados dentro dessa perspectiva objetivam buscar apoio da rede de atendimento intersetorial e a equipe se corresponsabiliza pelo cuidado. Nesse sentido, a expectativa não é de que haja um rompimento imediato, mas uma construção de alternativas em conjunto com a usuária. Por outro lado, se o entendimento for no sentido de que a equipe de saúde só pode ofertar ações relacionadas a encaminhamentos, prescrições e curativos para lesões físicas, há uma tendência de desresponsabilização da equipe e uma frustração quando esses encaminhamentos não são aceitos pela usuária.

Dessa forma, construiu-se o diagrama apresentado na Figura 1, identificando a categoria Condutas frente à violência de gênero contra a mulher como fenômeno central e estabelecendo a sua relação com as demais categorias e subcategorias para uma melhor compreensão das questões expostas. Para tanto, organizou-se as categorias de acordo com as condições que interferem no fenômeno (causais, intervenientes e contexto), as estratégias de ação/ interação e as consequências, consideradas como efeitos positivos ou negativos da ação/ interação (CHARMAZ, 2009).

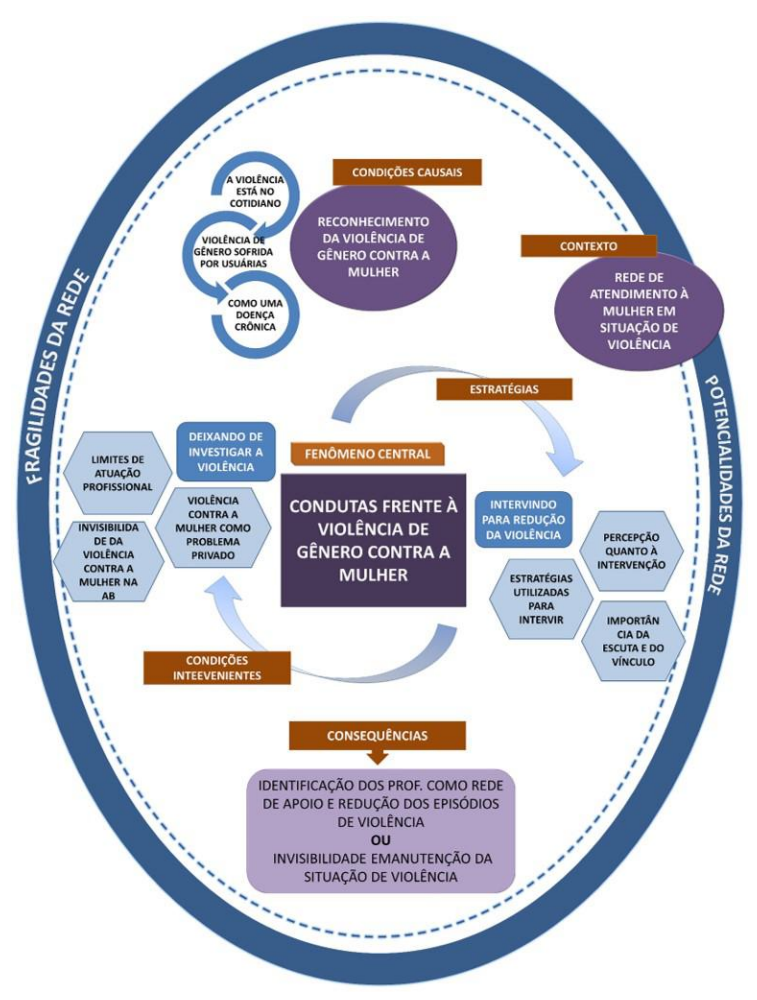

Figura 1: Diagrama da relação entre o fenômeno central e demais categorias Fonte: Elaborado pela autora.

\#PraTodoMundoVer A figura apresenta um diagrama dentro de um formato oval com formas geométricas nas cores roxo, lilás e laranja sobre um fundo branco. As CONDIÇÕES CAUSAIS, CONTEXTO, CONDIÇŌ̃ES INTERVENIENTES, ESTRATÉGIAS E CONSEQUÊNCIAS estão escritas em branco, dentro de retângulos laranja, próximos às categorias a que se referem. As categorias estão escritas em branco, dentro de círculos roxos, e as subcategorias estão escritas em branco, dentro de retângulos lilases. Acima, no primeiro círculo, está descrita a categoria RECONHECIMENTO DA VIOLÊNCIA DE GÊNERO CONTRA A MULHER, ligada às condições causais e às subcategorias violência no cotidiano, violência sofrida por usuárias e como uma doença crônica. À direita, no segundo círculo, está descrita a categoria REDE DE ATENDIMENTO À MULHER EM SITUAÇÃO DE VIOLÊNCIA, ligada ao contexto $e$ às subcategorias fragilidades $e$ potencialidades, conectada ao círculo maior que delimita a figura. Ao centro está o fenômeno central, representado pela categoria CONDUTAS FRENTE À VIOLẾNCIA DE GÊNERO CONTRA A MULHER, ligado por uma flecha à esquerda à subcategoria Deixando de agir frente à violência (por limites de atuação, invisibilidade e problema privado) como condições intervenientes e por outra flecha à direita à subcategoria Intervindo para redução da violência (através de escuta e vínculo, percepção sobre intervenção e estratégias para intervir) como estratégias de ação. As consequências são apresentadas em um retângulo abaixo, sendo: identificação dos profissionais como rede de apoio e redução dos episódios de violência ou invisibilidade e manutenção da situação de violência. 
A partir desse diagrama observamos que as subcategorias do fenômeno central explicam os fatores que interferem para que haja ou não uma intervenção sobre o problema e quais estratégias são utilizadas. As condições causais são apresentadas na categoria Reconhecimento da violência de gênero contra a mulher e suas subcategorias, que evidenciam a presença da violência contra a mulher no cotidiano das profissionais e das usuárias do serviço de saúde. 0 contexto que abrange o reconhecimento da violência contra a mulher e as atitudes e ações desenvolvidas frente a este problema é explicitado na categoria Rede de atendimento à mulher em situação de violência e apresenta fragilidades e potencialidades dessa rede.

As consequências podem ser diferentes, conforme as condutas tomadas, podendo favorecer o enfrentamento da violência contra a mulher a partir da construção de rede de apoio e ações que podem induzir à redução dos episódios de violência ou contribuir para a manutenção e invisibilidade do problema quando não há ação, ou quando as únicas ações ofertadas estão baseadas no modelo biomédico.

\section{Considerações finais}

Neste estudo, identificamos que as(os) profissionais da $A B$, a partir de diferentes contextos e histórias de vida, reconhecem a presença da violência de gênero contra as mulheres nos serviços de saúde, porém o que foi possível verificar é que em muitas situações não há intervenção. Observou-se que a decisão para intervir ou não em uma situação de violência é construída a partir da análise de alguns fatores: 1) O que a(o) profissional considera que pode ofertar para a usuária? (escuta, encaminhamento, prescrição, denúncia, notificação), 2) O que a(o) profissional espera com essa intervenção? (rompimento, diminuição da violência, construir rede de apoio), 3) É identificada uma rede de atendimento intersetorial que pode ser acionada? Estas questões determinam posicionamentos e condutas frente à violência e são importantes para a reflexão sobre as potencialidades da Saúde Coletiva e do trabalho realizado na Atenção Básica.

Os aspectos abordados apresentam a complexidade do problema e a grandeza do desafio que se coloca para que violência de gênero contra as mulheres possa ser reconhecida como um objeto de intervenção na área da saúde. Entre os caminhos que se abrem nessa trilha, apontamos algumas direções possíveis, e a principal delas é apostar nos espaços de encontro com as usuárias, no acolhimento, nas tecnologias leves, nas relações estabelecidas e na constituição de rede de apoio, principalmente a partir do trabalho das Equipes de Saúde da Família e dos(as) ACSs. Potencializar e dar suporte para as ações desenvolvidas por elas(es) pode favorecer a construção de uma rede de apoio às mulheres e de práticas voltadas ao enfrentamento da violência que elas sofrem.

Trazer as questões sobre violência de gênero contra as mulheres para o foco da saúde implica sua consideração no planejamento e prestação de serviços, desde ações preventivas até de identificação, intervenção e apoio às vítimas. Além disso, esta pesquisa evidenciou o caráter social da violência de gênero, que requer ações intersetoriais a fim de buscar romper com a invisibilidade do fenômeno, garantir o acolhimento das vítimas e a garantia dos seus direitos, assim como políticas públicas que tenham potencial para combater a base cultural que legitima a violência contra a mulher e para fomentar a formação de redes, para além do conjunto de diferentes serviços, promovendo intervenções mais comprometidas e articuladas.

\section{Referências}

BRASIL. Violência intrafamiliar: orientações para a prática em serviço. Cadernos de Atenção Básica, n. 8. Secretaria de Políticas de Saúde. Brasília: Ministério da Saúde, 2001.

BRASIL. Lei $n^{\circ}$ 10.778, de 24 de novembro de 2003. Estabelece a notificação compulsória, no território nacional, do caso de violência contra a mulher que for atendida em serviços de saúde públicos ou privados. Diário Oficial da União, 2003.

BRASIL. Prevenção e tratamento dos agravos resultantes da violência sexual contra mulheres e adolescentes: norma técnica. Ministério da Saúde. Secretaria de Atenção à Saúde. Departamento de Ações Programáticas Estratégicas. 3. ed. Brasília: Ministério da Saúde, 2012.

BRASIL. Protocolos da Atenção Básica: Saúde das Mulheres. Ministério da Saúde. Instituto SírioLibanês de Ensino e Pesquisa. Brasília: Ministério da Saúde, 2016.

CHARMAZ, Kathy. "Discovering Chronic Illness: Using Grounded Theory". Social Science \& Medicine, v. 30, n. 11, p. 1161-1172, 1990.

CHARMAZ, Kathy. A Construção da Teoria Fundamentada: guia prático para análise qualitativa. Porto Alegre: Artmed, 2009. 
CONTATORE, Octávio Augusto; MALFITANO, Ana Paula Serrata; BARROS, Nelson Filice de. "Os cuidados em saúde: ontologia, hermenêutica e teleologia". Interface (Botucatu), Botucatu, v. 21, n. 62, p. 553-563, set. 2017.

COUTO, Vinicius Assis et al. "Intersetorialidade e ações de combate à violência contra a mulher". Revista Estudos Feministas, Florianópolis, v. 26, n. 2, 2018.

D'OLIVEIRA, Ana Flávia Pires Lucas; SCHRAIBER, Lilia Blima. "Mulheres em situação de violência: entre rotas críticas e redes intersetoriais de atenção". Revista de Medicina, São Paulo, v. 92, n. 2, p. 134-140, abr./jun. 2013.

D'OLIVEIRA, Ana Flávia Pires Lucas et al. "Atenção integral à saúde de mulheres em situação de violência de gênero: uma alternativa para a atenção primária em saúde". Ciência \& Saúde Coletiva, v. 14, n. 4, p. 1037-1050, jul./ago. 2009.

ESPINAR-RUIZ, Eva; LOPEZ-MONSALVE, Begoña. "Infancia y violencia de género: cuantificación y percepciones". Revista Estudos Feministas, Florianópolis, v. 23, n. 2, p. 451-470, ago. 2015.

GARCIA, Leila Posenato; SILVA, Gabriela Drummond Marques da. "Violência por parceiro íntimo: perfil dos atendimentos em serviços de urgência e emergência nas capitais dos estados brasileiros, 2014". Cadernos de Saúde Pública, Rio de Janeiro, v. 34, n. 4, abr. 2018.

KRIMBERG VON MÜHLEN, Bruna; NEVES, Marlene. "Avanços e retrocessos no combate da violência contra mulheres". Athenea Digital, Barcelona, v. 13, n. 2, p. 229-237, jul. 2013.

MARQUI, Alessandra Bernadete Trovó de et al. "Caracterização das equipes da Saúde da Família e de seu processo de trabalho". Revista da Escola de Enfermagem da USP, São Paulo, v. 44, n. 4, p. 956-961, dez. 2010.

MARSIGLIA, Regina Maria Giffoni. "Perfil dos trabalhadores da atenção básica em saúde no município de São Paulo: região norte e central da cidade". Saúde \& Sociedade, São Paulo, v. 20, n. 4, p. 900911 , dez. 2011.

MENEGHEL, Stela Nazareth et al. "Feminicídios: estudo em capitais e municípios brasileiros de grande porte populacional”. Ciência \& Saúde Coletiva, Rio de Janeiro, v. 22, n. 9, p. 2963-2970, set. 2017.

MENEGHEL, Stela Nazareth; MARGARITES, Ane Freitas. "Feminicídios em Porto Alegre, Rio Grande do Sul, Brasil: iniquidades de gênero ao morrer”. Cadernos de Saúde Pública, Rio de Janeiro, v. 33, n. 12, dez. 2017.

MERHY, Emerson Elias; FEUERWERKER, Laura Camargo Macruz. "Novo olhar sobre as tecnologias de saúde: uma necessidade contemporânea". In: MANDARINO, Ana Cristina de S.; GOMBERG, Estélio (Orgs.). Leituras de novas tecnologias e saúde. São Cristóvão: EDUFS, 2009. p. 29-74.

MOREIRA, Tatiana das Neves Fraga et al. "A construção do cuidado: o atendimento às situações de violência doméstica por equipes de Saúde da Família". Saúde \& Sociedade, São Paulo, v. 23, n. 3 , p. 814-827, set. 2014 .

NAÇÕES UNIDAS. Declaration on the elimination of violence against women. $48^{a}$ Sessão Ordinária da Assembleia Geral das Nações Unidas. Resolução n A/RES/48/104. Nova York, EUA. Nova York: ONU, 1993.

OLIVEIRA, Rebeca Nunes Guedes de; FONSECA, Rosa Maria Godoy Serpa da. "Necessidades em saúde: a interface entre o discurso de profissionais de saúde e mulheres vitimizadas". Revista Latino-Americana de Enfermagem, Ribeirão Preto, v. 23, n. 2, p. 299-306, abr. 2015.

OLIVEIRA, Gabriela Cristina Costa de; PAES, Maione Silva Louzada. "Violência de gênero contra a mulher: a vivência deste fenômeno". Revista Enfermagem Integrada, Ipatinga, v. 7, n. 1, p. 12311246, jul./ago. 2014.

OMS. Violência contra a Mulher. Estratégia e Plano de Ação sobre o Fortalecimento do Sistema de Saúde para Abordar a Violência contra a Mulher. Organização Pan-Americana da Saúde. Organização Mundial da Saúde, 2015.

RODRIGUES, Luciana Santos; CHALHUB, Anderson Almeida. "Contextos familiares violentos: da vivência de filho à experiência de pai”. Pensando Famílias, Porto Alegre, v. 18, n. 2, p. 77-92, dez. 2014. 
SAFFIOTI, Heleieth. Gênero, Patriarcado, Violência. 2. ed. São Paulo: Expressão Popular; Fundação Perseu Abramo, 2015.

SANTOS, Cecília MacDowell. "Curto-circuito, falta de linha ou na linha? Redes de enfrentamento à violência contra mulheres em São Paulo". Revista Estudos Feministas, Florianópolis, v. 23, n. 2, p. 577-600, ago. 2015.

SCHRAIBER, Lilia Blima et al. "Violência contra mulheres entre usuárias de serviços públicos de saúde da Grande São Paulo". Revista de Saúde Pública, São Paulo, v. 41, n. 3, p. 359-367, jun. 2007.

SCHRAIBER, Lilia Blima; D'OLIVEIRA, Ana Flávia Pires Lucas. "Romper com a violência contra a mulher: como lidar desde a perspectiva do campo da saúde". In: MENEGHEL, Stela Nazareth (Org.). Rotas críticas Il: ferramentas para trabalhar com a violência de gênero. Santa Cruz do Sul: EDUNISC, 2009. p. 131-141.

SIGNORELLI, Marcos Claudio; TAFT, Angela; PEREIRA, Pedro Paulo Gomes. "Violência doméstica contra mulheres, políticas públicas e agentes comunitários de saúde na Atenção Primária à Saúde no Brasil". Ciência \& Saúde Coletiva, Rio de Janeiro, v. 23, n. 1, p. 93-102, jan. 2018.

SILVA, Ethel Bastos da; PADOIN, Stella Maris de Mello; VIANNA, Lucila Amaral Carneiro. "Violência contra a mulher e a prática assistencial na percepção dos profissionais da saúde". Texto \& Contexto Enfermagem, Florianópolis, v. 24, n. 1, p. 229-237, jan./mar. 2015.

SILVA, Neuzileny Nery Ferreira et al. "Atuação dos enfermeiros da atenção básica a mulheres em situação de violência". Enfermagem em Foco, Brasília, v. 8, p. 70-74, 2017.

SOARES, Juliana de Lima et al. "Tecitura do vínculo em saúde na situação familiar de adoecimento crônico". Interface (Botucatu), Botucatu, v. 20, n. 59, p. 929-940, dez. 2016.

STREY, Marlene Neves; WERBA, Graziela C. "Longe dos olhos, longe do coração: ainda a invisibilidade da violência contra a mulher”. In: GROSSI, Patrícia Krieger (Org.). Violências e gênero: coisas que a gente não gostaria de saber. 2. ed. Porto Alegre: EDPUCRS, 2012. p. 73-82.

TRAD, Leny A. Bomfim. "Grupos focais: conceitos, procedimentos e reflexões baseadas em experiências com o uso da técnica em pesquisas de saúde”. Physis, Rio de Janeiro, v. 19, n. 3, p. 777-796, 2009.

VARGAS, Regina. "A integralidade da atenção à saúde na percepção de profissionais da rede". In: NEGRÃO, Télia; VARGAS, Regina; RODRIGUES, Leina Peres (Orgs.). Saúde Mental e gênero: novas abordagens para uma linha de cuidado. Porto Alegre: Coletivo Feminino Plural, 2015. p. 13-40.

VENTURINI, Gustavo; GODINHO, Tatau (Orgs.). Mulheres brasileiras e gênero nos espaços público e privado: uma década de mudanças na opinião pública. São Paulo: Fundação Perseu Abramo; SESC, 2013

VIEIRA, Elisabeth Meloni; HASSE, Mariana. "Percepções dos profissionais de uma rede intersetorial sobre o atendimento a mulheres em situação de violência". Interface (Botucatu), Botucatu, v. 21 , n. 60, p. 52-62, mar. 2017.

WERMELINGER, Mônica et al. "A Força de Trabalho do Setor de Saúde no Brasil: Focalizando a Feminização". Divulgação em Saúde para Debate, Rio de Janeiro, n. 45, p. 55-71, abr. 2010.

Paula Suséli Silva de Bearzi (paula.bearzi@universo.univates.br) é graduada em Odontologia pela Universidade Federal de Santa Maria. Possui Mestrado em Saúde Coletiva, Especialização em Preceptoria no SUS e em Saúde Coletiva, Residência Integrada em Saúde pela Escola de Saúde Pública/RS. Professora do curso de Odontologia da UNIVATES. Pesquisadora nas áreas de Violência de Gênero, Planejamento em Saúde, Saúde Bucal Coletiva e Saúde Coletiva.

Aline Blaya Martins (00166107@ufrgs.br) possui Graduação em Odontologia pela PUC/ RS. Especialista em Saúde Coletiva. Mestre e Doutora em Odontologia - Saúde Bucal Coletiva pela UFRGS. Professora Adjunta da Faculdade de Odontologia da UFRGS. Coordenadora do Programa de Pós-Graduação em Saúde Coletiva da UFRGS e da Residência Integrada em Saúde Bucal. Pesquisadora nas áreas de Gestão, Educação e Saúde e Atenção à Saúde de Populações Vulneráveis. 
Renato José De Marchi (renato.marchi@ufrgs.br) é Professor Adjunto do Departamento de Odontologia Preventiva e Social da UFRGS. Professor do Programa de Residência Integrada em Saúde Bucal e do Programa de Pós-Graduação em Saúde Coletiva da UFRGS. Graduado em Odontologia pela UFRGS. Mestre e doutor em Odontologia - Saúde Bucal Coletiva, UFRGS. Pesquisador nas áreas de Saúde Bucal Coletiva, Odontogeriatria, Pesquisa Qualitativa e Educação em Saúde.

Aline Rodrigues Reser (japareser@gmail.com) possui Graduação em Enfermagem pela UFSM e em Saúde Coletiva pela UFRGS. Especialista em Saúde Pública, Residência Integrada em Saúde com ênfase em Atenção Básica em Saúde Coletiva e curso de Sanitarista certificado pela Escola Nacional de Saúde Pública Sérgio Arouca. Possui Mestrado em Saúde Coletiva. Pesquisadora nas áreas de Saúde Coletiva, Apoio Institucional, Estratégia Saúde da Família e Vigilância em Saúde.

\section{COMO CITAR ESSE ARTIGO DE ACORDO COM AS NORMAS DA REVISTA}

BEARZI, Paula Suséli Silva de; MARTINS, Aline Blaya; DE MARCHI, Renato José; RESER, Aline Rodrigues. "Trilhas para o enfrentamento da violência contra a mulher". Revista Estudos Feministas, Florianópolis, v. 28, n. 3, e60162, 2020.

\section{CONTRIBUIÇÃO DE AUTORIA}

Paula Suséli Silva de Bearzi foi responsável pela concepção, planejamento e execução da pesquisa de campo, análise das informações e preparação do artigo.

Aline Blaya Martins contribuiu com a concepção, planejamento, desenvolvimento, análise das informações, supervisão da pesquisa e revisão final do artigo.

Renato José De Marchi realizou a proposição metodológica, análise das informações, supervisão da pesquisa e revisão final do artigo.

Aline Rodrigues Reser contribuiu na interpretação das informações e revisão final do artigo.

\section{FINANCIAMENTO}

Não se aplica.

\section{CONSENTIMENTO DE USO DE IMAGEM}

Não se aplica.

\section{APROVAÇÃO DE COMITÊ DE ÉTICA EM PESQUISA}

Este estudo foi aprovado pelo Comitê de Ética em Pesquisa da Universidade Federal do Rio Grande do Sul, parecer $n^{\circ}$ CAAE 69737517.0.0000.5347, e os(as) participantes autorizaram o uso das informações mediante assinatura do Termo de Consentimento Livre e Esclarecido.

\section{CONFLITO DE INTERESSES}

Não se aplica.

LICENÇA DE USO

Este artigo está licenciado sob a Licença Creative Commons CC-BY International. Com essa licença você pode compartilhar, adaptar, criar para qualquer fim, desde que atribua a autoria da obra.

\section{HISTÓRICO}

Recebido em 10/11/2018

Reapresentado em 02/12/2019

Aprovado em 06/04/2020 